\title{
Brincando em sala na Educação Infantil? Reflexões acerca da organização dos espaços para experiências na primeira infância
}

\section{Playing in the classroom in the Early Childhood Education? Reflections on the organization of spaces for early childhood experiences}

\section{Jugando en el sala de Educacion Infantil? Reflexiones en torno a la organización de espacios para las experiencias de la primera infancia}

\author{
Maria Elisa Nicolielo ${ }^{1}$ \\ Aline Sommerhalder ${ }^{1}$ \\ Fernando Donizete Alves ${ }^{1}$
}

DOI: http://dx.doi.org/10.20435/serie-estudos.v23i47.1054

\begin{abstract}
Resumo: Origina-se de uma pesquisa concluída e tece considerações acerca da organização do espaço, para brincar, em sala de Educação Infantil. Fundamentou-se em autores como: Brougère, Gandini, Freire, Cruz e Rinaldi. De que maneira as crianças estão brincando no espaço de sala de Educação Infantil? Que práticas educativas estão relacionadas à organização do espaço em sala, em contexto de brincadeiras na Educação Infantil? Objetivou identificar e problematizar a organização espacial de sala de Educação Infantil, para o brincar infantil. De abordagem qualitativa, utilizou observação participante de momentos do brincar de 14 crianças e a respectiva professora, produzindo treze diários de campo. As crianças manifestaram curiosidades e interagiram entre si, reinventando e resignificando os espaços possíveis na sala. Além de brincarem sentadas à mesa ou no chão, esse grupo manifestou apreço por brincar embaixo da mesa, por proporcionar liberdade às ações e relações entre subgrupos de crianças. A pesquisa mostrou uma ênfase no brincar em sala, com pouca exploração de outros espaços da instituição. Conclui que, quando o espaço é organizado de forma variada, as possibilidades de criação e relações aumentam, ampliando o incentivo de brincadeiras, de experimentações, de descobertas, de perpetuação e reinvenção da cultura lúdica infantil e, com isso, de melhores oportunidades educativas para as crianças.
\end{abstract}

Palavras-chave: brincar; crianças; espaços na Educação Infantil.

${ }^{1}$ Universidade Federal de São Carlos (UFSCar), São Carlos, São Paulo, Brasil. 
Abstract: It originates from a completed research and weaves considerations about the organization of space, to play in classroom in the Early Childhood Education. It was based on authors such as: Brougère, Gandini, Freire, Cruz and Rinaldi. How are the children playing in the space of classroom in the Early Childhood Education? What pedagogical practices are related to the organization of space in the classroom, in the context of play Early Childhood Education? The objective of this study was to identify and problematize the spatial organization of the classroom in the Early Childhood Education for children 's play. From a qualitative approach, she used participant observation of playing moments of 14 children and the respective teacher, producing thirteen field diaries. The children expressed curiosities and interacted with each other, reinventing and reframing the possible spaces in the classroom. In addition to playing seated at the table or on the floor, this group expressed appreciation for playing under the table, for giving freedom to actions and relationships between subgroups of children. The research showed an emphasis on play in the classroom, with little exploration of other spaces of the institution. The research showed an emphasis on play in the classroom, with little exploration of other spaces of the institution. It concludes that, when space is organized in a varied way, the possibilities of creation and relationships increase, increasing the incentive of play, experimentation, discoveries, perpetuation and reinvention of the children's play culture and with this, of better educational opportunities for children.

Keywords: play; children; spaces in Early Childhood Education.

Resumen: Tiene su origen en una investigación elaborada y teje consideraciones sobre la organización del espacio para jugar en la sala de educación infantil. Se basaba en autores como: Brougère, Gandini, Freire, Cruz y Rinaldi. Cómo los niños están jugando en el espacio de la sala de Educación Infantil? ¿Qué prácticas pedagógicas están relacionados con el organización de el espacio de la sala de clase en el contexto del juego en la educación infantil? Tuvo como objetivo identificar y analizar la organización espacial de la sala de educación infantil para el juego infantile. Los datos fueron recolectados a través de momentos de observación participante de juego de 14 niños y su maestra, lo que resulta en trece diarios de campo. Los niños mostraron curiosidad e interactuaron entre sí, reinventando y redefinindo los espacios posibles en la sala. Además de jugar en la mesa o en el suelo, este grupo expresó su gusto por jugar por debajo de la mesa, permitiendo libertad a las acciones y las relaciones entre los subgrupos de niños. La investigación ha demostrado un énfasis en jugar en la sala con poca exploración de otras áreas de la institución. Concluye que cuando el espacio se organiza de diferentes maneras, aumentan las posibilidades de crear y de relaciones, ampliando el incentivo a los juegos, ensayos, descubrimientos, perpetuación y la reinvención de la cultura de los juegos infantiles y, por tanto, mejores oportunidades de educación para los niños.

Palabras clave: juego; niños; espacios en Educación Infantil.

\section{INTRODUÇÃO}

O artigo origina-se de uma pesquisa concluída, realizada pelo Grupo de Estudos e Pesquisas sobre Processos Educativos de Crianças em Contextos/CNPq, que abordou processos de ensinar e de aprender que ocorreram nas relações entre 
crianças e entre elas e uma professora, em contexto de brincar livre ${ }^{2}$ na Educação Infantil. Tece considerações sobre o espaço para brincar, em sala de Educação Infantil. Parte do reconhecimento de que o espaço é um contexto educativo e brincar é experiência humana, sendo que essa experiência possibilita processos de ensinar e de aprender para a vida da criança. De que maneira crianças estão brincando no espaço de sala de Educação Infantil? Que práticas educativas de professores (as) estão relacionadas à organização do espaço em sala, em contexto de brincadeiras na Educação Infantil? Essas interrogações mobilizaram o desencadeamento desse artigo, que teve como objetivo identificar e problematizar a organização espacial de sala de Educação Infantil, para as brincadeiras de crianças.

De acordo com as Diretrizes Curriculares Nacionais para a Educação Infantil (BRASIL, 2010), essa etapa educativa vem sendo repensada, a fim de fortalecer práticas pedagógicas mediadoras de aprendizagens e desenvolvimento infantis. Nesse sentido, também se considera a atualidade da educação brasileira, por meio da Lei 12.796 (BRASIL, 2013) quando incluiu a pré-escola como etapa obrigatória da educação básica. Com isso, há o reconhecimento na instância legal da obrigatoriedade do atendimento em ambientes educativos coletivos de crianças pequenas.

Desde a Constituição Federal de 1988, seguida da Convenção dos Direitos da Criança, aprovado pelas Nações Unidas em 1989 e tantas outras leis e convenções destinadas à Educação Infantil (BRASIL, 1998; 2010) assiste-se a aprovação de um conjunto de direitos fundamentais e inerentes às infâncias e as crianças. $O$ artigo $15^{\circ}$, parágrafo único, do Estatuto da Criança e do Adolescente aponta: "A criança e o adolescente têm direito à liberdade, ao respeito e à dignidade como pessoa humana em processo de desenvolvimento e como sujeitos de direitos civis, humanos e sociais garantidos na Constituição e nas leis" (BRASIL, 1990).

Contudo e, apesar de todo o aparato legal destinado ao atendimento de crianças enquanto cidadãos de direitos e deveres, elas têm tido poucas oportunidades para se colocarem e se compreenderem como autoras de suas ações. Ainda predomina a visão de infâncias como o período para "aquele que não fala" (CRUZ, 2008, p. 11).

\footnotetext{
${ }^{2}$ Nesse artigo, brincar livre é compreendido como experiência lúdica espontânea da criança, em que ela tem a possibilidade de escolher com quem, de qual brincadeira, onde e com o que brincar.
} 
Larrosa (2013, p. 187) argumenta que "a criança expõe-se completamente ao nosso olhar, se oferece absolutamente às nossas mãos e se submete, sem resistência, para que cubramos com nossas ideias, nossos sonhos e nossos delírios". Esse pensamento pode ser entendido mediante a compreensão da trajetória histórica literária e artística sobre crianças, a qual se consolidou em um lento processo de reconhecimento social das infâncias e de pouco respeito às crianças (ARIÈS, 1981; KUHLMANN, 1998; POSTMAN, 1999).

Bacha (2012) destaca que, até o século XVII, a criança era vista como um fardo, um estorvo. Na melhor das hipóteses, assumia uma posição insignificante. A partir do século XVIII, a concepção de criança sofreu intensas modificações, de modo que ela passou a ser considerada como um ser frágil e, portanto, necessitando de extremos cuidados. Operou-se na história a compreensão de crianças como sujeitos, atores sociais e produtoras de cultura que afetam e são afetadas pelas sociedades (CORSARO, 2011). A visão assumida neste artigo é por uma concepção que reconheça o que é específico das crianças, entendendo-as como cidadãs que adquirem, produzem cultura e são nela produzidas, pois nessa ótica fica mais fértil o exercício de aproximação do universo da criança e do modo como esta busca compreender o mundo.

Tem-se neste estudo a visão de criança como sujeito dotado de potencial para produzir conhecimentos e atribuir sentidos próprios aos elementos do mundo que a cerca. Trata-se de crianças capazes de dizer a própria palavra (FIORI, 1991), de trocar e significar experiências com as outras crianças e com os adultos em diferentes espaços, podendo expressar o que sentem. De maneira análoga, as Diretrizes Curriculares Nacionais para a Educação Infantil (BRASIL, 2010, p. 12) reforçam esse olhar, ao definir a criança como:

[...] sujeito histórico e de direitos que, nas interações, relações e práticas cotidianas que vivencia, constrói sua identidade, pessoal e coletiva, brinca, imagina, fantasia, deseja, aprende, observa, experimenta, narra, questiona e constrói sentidos sobre a natureza e a sociedade, produzindo cultura.

Em diálogo com esse contexto, Freire (2000) argumenta que, por sermos seres sócio-históricos, estamos no mundo não para a ele se adaptar como meros espectadores, mas para transformá-lo como atores da história. O autor reforça a compreensão de que as crianças são sujeitos, e sujeitos de direitos, pois nossa presença no mundo não é neutra, implica escolha e decisão (FREIRE, 2000). 
Nesse sentido, Dalarri e Korczak (1989, p. 21) defendem que "a criança é um ser humano, é uma pessoa, que dependeu de outras para se revelar, mas que possivelmente abrirá para outras o caminho da vida [...]. Toda criança nasce com o direito de ser". Assim, a criança é um outro - concreta e singular - não a partir daquilo que ocorre de projeção sobre ela; é um outro porque sempre é outra coisa diferente do que podemos antecipar, porque sempre está além do que sabemos, do que queremos ou do que esperamos dela.

Como protagonistas, as crianças deveriam ser respeitadas e notadas em sua atividade primordial que é o brincar (KISHIMOTO, 2003). Gobbi e Pinazza (2014) defendem que é preciso reconhecer as inúmeras linguagens das crianças, as enxergamos como sujeitos na contemporaneidade, sujeitos de direitos, e não como um projeto de humano para o futuro. Borba (2007) acrescenta que as crianças se expressam a partir de inúmeras linguagens, por exemplo, pinturas, danças, brincar, gestos e olhares. Entre estas, brincar é reconhecido como a linguagem da criança por excelência, pois, a partir do brincar, elas expõem suas ideias, sentimentos, imaginação e compreensão do mundo, ao seu redor.

Em contextos de brincadeiras, elas ainda expressam seus interesses, suas emoções, as compreensões que elaboram da realidade a sua volta, vivenciam a realidade da forma como desejam, por exemplo, protagonizando personagens ao construírem histórias de faz-de-conta. Na realidade imaginária, experienciam situações de coragem, conflito, prazer, tensão, interesses e possibilidades, aflorando desejos, por vezes, irrealizáveis, e a sua capacidade imaginativa de realizar tais desejos.

Ao se relacionarem com seus pares, com os adultos e com os objetos lúdicos, como os brinquedos, que são disponibilizados ou criados por elas para exploração em sala ou fora dela, as crianças se apropriam de elementos das diversas culturas, transmitem, podem produzir e fortalecer a própria cultura lúdica infantil ${ }^{3}$.

As Diretrizes Curriculares Nacionais para a Educação Infantil (BRASIL, 2010) mencionam que as práticas pedagógicas dessa etapa da educação devem ter como eixos norteadores as interações e a brincadeira. De tal modo, na Educação Infantil, brincar se faz presente de várias formas, como no oferecimento de brinquedos entre uma atividade e outra, o dia de ida ao parque, realização de brincadeiras

3 De acordo com Brougère (1998), a cultura lúdica é um conjunto de regras, características, significações próprias da brincadeira e que as crianças adquirem quando brincam. 
coletivas no pátio ou em outros espaços da instituição e a utilização do brincar com a intencionalidade de aquisição ou aprimoramento de habilidades infantis.

Friedmann (2013) destaca que, a partir das linguagens infantis, podemos descobrir as singularidades das crianças, suas essências em profundidade. Anuncia que a construção dessas linguagens se inicia com as brincadeiras. As crianças estão em toda parte, e cada uma com suas particularidades. Quando brincam, falam de seus sonhos, medos, fantasias, realidades, manifestam-se por meio de linguagens não verbais. Por isso, não podemos impedir as crianças de imaginar, sonhar e brincar.

Em contrapartida, essa autora argumenta que, no século XXI, os espaços e oportunidades para as crianças imaginarem, criarem, se expressarem por meio de brincadeiras e desenhos estão cada vez mais sendo controlados e tolhidos de sua rotina, tanto na escola, como na família. Mesmo quando são oportunizados momentos de brincadeiras para as crianças, em que elas fantasiam, criam, constroem, trocam experiências, aprendem e ensinam, o reconhecimento dessas práticas como oportunidades para processos educativos ainda é incipiente. Um exemplo é a organização dos espaços para brincar, principalmente na Educação Infantil.

Ocorridos na maioria das vezes dentro de sala, os momentos de brincadeiras oferecidos às crianças nem sempre oportunizam a exploração e invenção de novas brincadeiras. Comumente, altera-se uma mobília de lugar, mas por opção do(a) professor(a). Por vezes, ele se esquece dos sujeitos principais que irão usufruir daquele espaço, ou seja, as próprias crianças.

Carvalho (2009) destaca que há vários arranjos espaciais em sala, entre estes, o espacial aberto, com espaços centrais vazios; o semiaberto, em que há organização de áreas delimitadas ou cantinhos para as crianças brincarem, em subgrupos. Apontam ainda essas autoras que as crianças preferem brincar e interagem mais com outras crianças, quando a sala está organizada em cantinhos, em arranjo espacial semiaberto. As Diretrizes Curriculares Nacionais para a Educação Infantil (BRASIL, 2010) indicam que é necessário garantir condições para o trabalho coletivo, no que diz respeito aos "Descolamentos e os movimentos amplos das crianças nos espaços internos e externos às salas de referência das turmas e à instituição" (BRASIL, 2010, p. 20).

Sommerhalder e Alves (2011) ensinam que a participação do professor na brincadeira das crianças inicia com o momento em que este organiza o espaço para 
brincar, seleciona materiais, modifica o espaço de acordo com as necessidades das crianças, as intencionalidades educativas, considerando ainda os limites que o espaço oferece, transformando-o em um ambiente pedagógico. Silva e Lima (2015) também apontam que as intervenções docentes nas brincadeiras das crianças são importantes para a ampliação da cultura lúdica e para a qualidade do brincar, na Educação Infantil. Segundo os autores, as intervenções pedagógicas diretas, por parte da professora, contribuem na mudança da concepção em relação à brincadeira. No entanto o estudo realizado pelos autores aponta diversos empecilhos que dificultam o emprego dessas mediações no dia a dia.

No âmago da discussão, ressalta-se a importância de práticas pedagógicas imbricadas no brincar que contribuam com o desenvolvimento integral das crianças, entendidas como sujeitos, desde os seus primeiros anos de vida. Ressalta-se a importância da sistematização empregada pelo professor na organização dos espaços da sala, de modo a oportunizar um ambiente propiciador de relações entre as crianças e entre elas e o professor. A organização da sala diz muito daquilo que o professor intenciona com sua prática. "O educador organiza o espaço de acordo com suas ideias sobre o desenvolvimento infantil e de acordo com seus objetivos, mesmo sem perceber" (CARVALHO; MENEGHINI, 2009, p. 152). Desse modo, é imprescindível compreender que suas ações pedagógicas, expressas na disponibilização de tempos e espaços de qualidade para brincar, corroboram para que as crianças construam e signifiquem a cultura lúdica.

\section{PERCURSO METODOLÓGICO}

Considerando que a brincadeira é um dos eixos norteadores das práticas pedagógicas que compõem as propostas curriculares da Educação Infantil, determinada nas Diretrizes Curriculares Nacionais para a Educação Infantil (BRASIL, 2010), a pesquisa de campo foi realizada em uma instituição municipal de Educação Infantil, de uma cidade do interior do estado de São Paulo, com um grupo de 14 crianças (oito meninas e seis meninos) com idade média de 3 anos, matriculadas em turma de Maternal II do período da manhã, e a respectiva professora. A escolha por esse grupo decorreu da consideração de que há um imaginário social sobre a idade da criança relacionada com menor ou frágil capacidade de ensinar e de aprender, fortalecendo práticas exclusivamente assistenciais das crianças, na Educação Infantil. 
Caracterizou-se como uma pesquisa de abordagem qualitativa, que teve como principal característica o aprofundamento no mundo dos significados das ações e relações humanas (MINAYO, 1994). Procedeu-se observação participante do brincar livre às sextas-feiras, por um tempo de 60 minutos, durante três meses consecutivos. A escolha por esse dia da semana ocorreu pelo fato de o mesmo ser o único dia e período disponível, em rotina, para as crianças escolherem do que e com quem brincar, além de poderem trazer brinquedos para a instituição. De acordo com Ludke e André (2012), a observação participante é uma técnica de coleta de dados importante na pesquisa qualitativa, pois possibilita ao pesquisador um contato pessoal com a situação pesquisada, fazendo com que ele experiencie diretamente essa situação e acompanhe as experiências diárias dos sujeitos.

Desse modo, estabeleceu-se um processo de convivência com as crianças e com a professora, permeado pelo diálogo, respeito e confiança. Baseado na compreensão de Oliveira (2009), sustentamos as observações participantes pelo viés da "convivência metodológica" que aponta a necessidade de essa convivência se caracterizar como um elemento metodológico de pesquisa.

Foram realizadas treze inserções ${ }^{4}$ de observação participante com registros em diários de campo. A técnica do diário de campo se caracteriza por ser um relato escrito daquilo que o pesquisador viu, ouviu, experienciou e pensou no decorrer da pesquisa (BOGDAN; BIKLEN, 1994). A escolha por esse instrumento decorreu do fato de que o diário de campo é um auxílio importante para a memória do pesquisador, pois aspectos cruciais da pesquisa podem ser revelados a partir desse instrumento, permitindo um olhar aprofundado para a análise da situação pesquisada (COSTA, 2002).

Para a apresentação e discussão dos resultados, todo o material produzido na fase de coleta foi agrupado via densas leituras e analisado tomando como inspiração a análise de conteúdo, proposta por Bardin (2009).

Ressalta-se que foram respeitados todos os cuidados éticos no que se refere ao consentimento de participação, ao anonimato das participantes, por meio de nomes fictícios (escolhidos pelos/as próprios/as participantes) e à confidencialidade dos dados. O estudo foi aprovado pelo Comitê de Ética em Pesquisa com Seres Humanos, da Universidade, sob parecer n. 791.060.

\footnotetext{
${ }^{4}$ Sessões de coleta de dados.
} 


\section{RESULTADOS E DISCUSSÃO}

O presente artigo apresenta um recorte dos resultados encontrados. $\mathrm{Na}$ sala do Maternal II, local em que a pesquisa foi realizada, havia três mesas de seis lugares cada uma, a mesa da professora, quatro armários (dois para cada período), uma lousa, ventilador, espelho, lixo e um baú com brinquedos. A sala era bem colorida, com vários desenhos nas paredes e nos armários. Também tinha cartazes, alfabeto, calendário e balões com datas de aniversários das crianças. O ambiente era fresco, arejado e com boa iluminação.

As mochilas das crianças ficavam no chão, encostadas na parede. A decoração era feita a partir das histórias trabalhadas na apostila (o sistema de ensino do município é apostilado). Assim, nas paredes dessa sala, feitos em material emborrachado, havia os três porquinhos e o lobo, da história "Os três porquinhos", e a personagem cachinhos dourados e a família urso, devido à história "Cachinhos Dourados". Na lousa, foram colocadas formas geométricas, também de material emborrachado.

A organização da sala, durante a coleta de dados, prevaleceu sempre da mesma maneira, ou seja, com três mesas, dispostas mais ou menos no centro da sala e em alguns dias a professora juntou duas ou três mesas para que as crianças brincassem juntas. Assim, esse grupo de crianças se organizou para brincar sentado no chão, em cadeiras que estavam junto às mesas ou embaixo das mesas e, majoritariamente esse brincar deu-se em sala. 


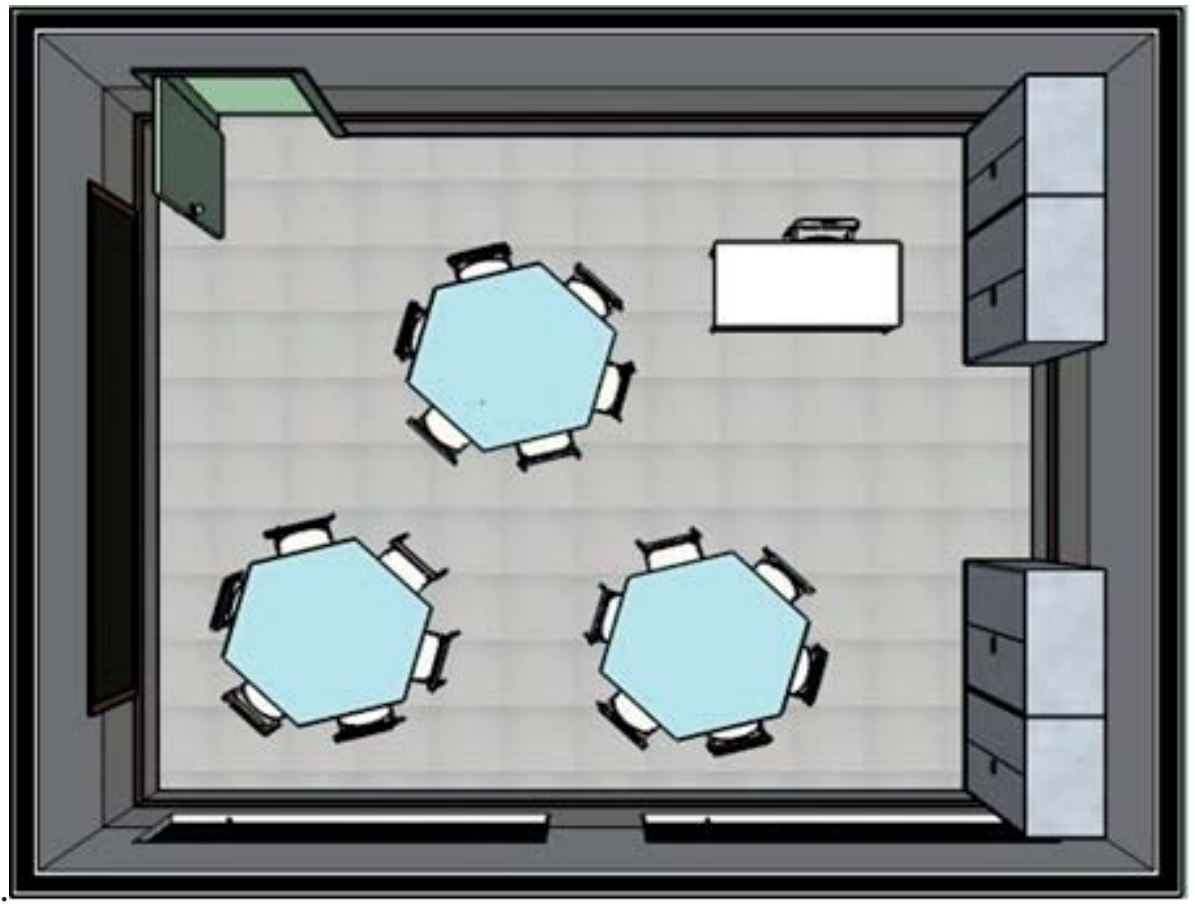

Figura 1 - Sala vista de cima

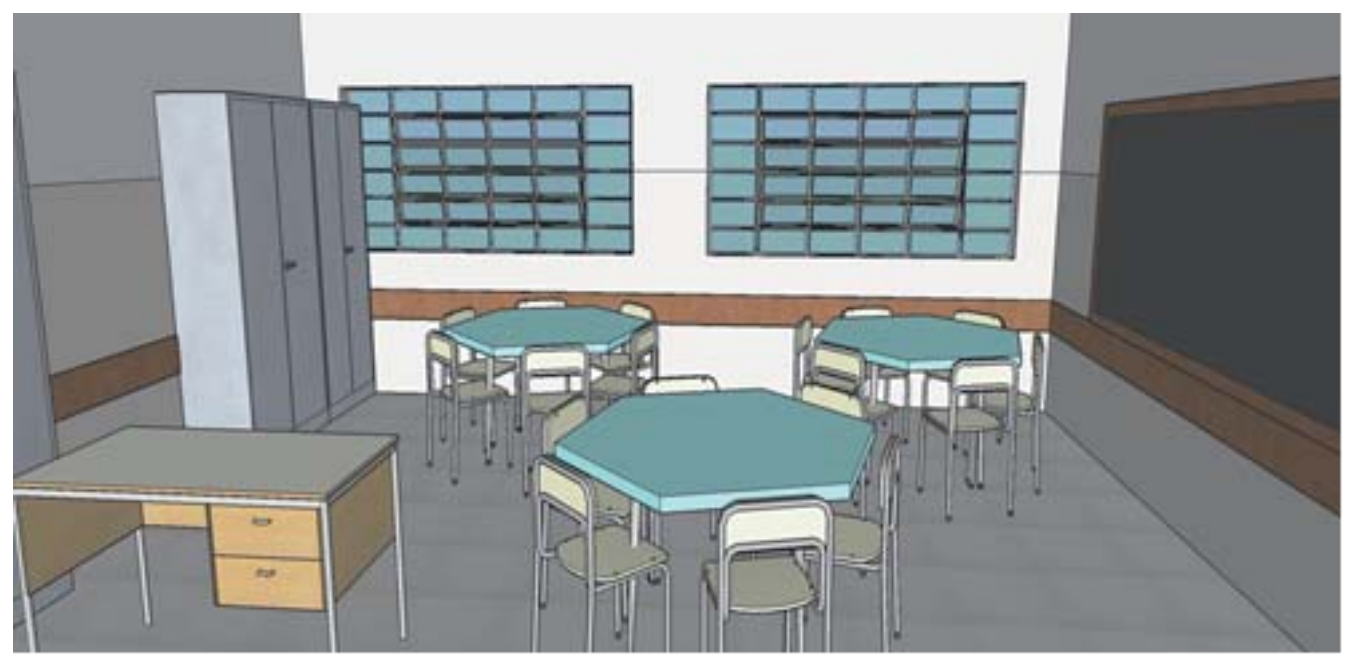

Figura 2- Sala vista da entrada 
De modo geral, as crianças manifestavam curiosidades e interagiam entre si, reinventando e (re)significando os espaços possíveis nessa sala. Muitas vezes, elas iniciavam uma brincadeira de movimento corporal, como correr atrás do colega, mas logo eram impedidas de continuar o movimento, a partir da solicitação feita pela professora, argumentando que o espaço físico da sala era pequeno e cheio de móveis e materiais, o que poderia comprometer a segurança das crianças e desencadear algum acidente.

Abaixo, trechos de diário de campo demonstram essa cena:

Hulk pega a máscara de tigre de pelúcia que, na verdade, é uma touca que o Miguel trouxe, e entrega ao Sidney em troca da máscara do Batman. Sidney vem assustar Moranguinho, fazendo gestos com a máscara de tigre, mas depois não quer mais o objeto lúdico e entrega para a menina Moranguinho, dizendo:

Sidney: É a sua vez.

Sidney quer pegar de volta a máscara do Batman que está com Hulk e diz: Sidney: É a minha vez! É a minha vez!

Moranguinho com a máscara de tigre sai correndo atrás de Sidney pela sala. Professora diz: Na sala não pode correr, porque o espaço é pequeno e cai. Os dois param de correr.

Ben 10 pega a máscara que está com Moranguinho, tirando do seu rosto sem pedir, mas ela não diz nada e sai correndo junto com ele e Sidney. Josi pergunta para Ben 10:

Josi: Deixa eu pôr um pouquinho?

Ben 10 não diz nada e continua correndo pela sala junto com Sidney e Moranguinho. (Diário de Campo 6)

Hulke Ben 10 correm pela sala.

Professora: Lembram da regrinha, que se correr pode cai?. Aqui tem muitas coisas perigosas e pode machucar. Lá fora pode correr.

Ben 10 imita um gatinho e vem engatinhando pelo chão fazendo sons que lembram um miado, com a sua boca.

Homem Aranha brinca com uma bola azul de plástico e depois pega o caminhão do Ben 10. Ben 10 vai rápido tirar de sua mão e não empresta para ele. Ben 10: Não, não!

Homem Aranha sai sem falar nada e vai à frente do espelho brincar de fazer gestos e expressões.

Ben 10 continua brincando de gato, e Ale interage com ele.

Ale: Ó não deixo o gato pegar a bola.

Ben 10 sai atrás da bola e começa a correr. Homem Aranha e Hulk também correm. 
A professora age rapidamente, tirando a bola dos meninos, porque estavam correndo pela sala.

Professora diz: Vocês não seguiram as regrinhas. (Diário de Campo número 13)

Durante o período de coleta, as crianças brincaram com frequência, sentadas, em cadeiras organizadas e que estavam próximas à mesa.

Na sala, as crianças já estavam brincando. As três mesas da sala estavam juntas, e as crianças sentadas em volta delas. Meninos e meninas brincando juntos. (Diário de Campo número 3)

Até o momento, as meninas não saíram da mesa. Ficaram brincando de desenhar. Somente uma resolveu se levantar. Os meninos também ficaram sentados o tempo todo, não exploraram os outros espaços da sala. (Diário de Campo número 7)

Sobre esse acontecimento, Finco (2007) salienta que as possibilidades de movimentar e trabalhar com o corpo diminui razoavelmente quando as crianças permanecem em sala e pouco exploram outros espaços da instituição. Assim, ao mesmo tempo em que se propicia o brincar, controlam-se os corpos das crianças. A brincadeira faz com que as crianças se movimentem, explorem os espaços. No entanto, ao organizar espaços restritos, com mesas e cadeiras, esses movimentos não são incentivados, tampouco explorados em suas potencialidades de linguagem corporal da criança.

Para Carvalho (2009), a sala de Educação Infantil deve estar organizada de maneira a oferecer espaços mais vazios para que as crianças desenvolvam as capacidades motoras básicas, ou seja, saltem, corram, agachem, façam movimentos coordenados; experimentem seu corpo. Nesse caso, uma possibilidade seria afastar as mesas no momento do brincar para que as crianças aproveitassem melhor todo o espaço da sala, uma vez que esse brincar pouco ocorreu em outros espaços. Se, mesmo assim, a organização espacial ainda estivesse imprópria para determinadas ações corporais, outros ambientes da instituição deveriam ser explorados nesse momento de brincar livre, como o pátio, parque, corredores, desde que estes estivessem disponíveis e adequados para uso.

O espaço de sala também deve ser reorganizado de tempo em tempo para convidar as crianças a realizarem novas experimentações (CARVALHO; MENEGHINI, 2009). Quando o espaço é organizado de forma variada, as crianças vivenciam inúmeras experiências, dentre elas, reforçam a sociabilidade, aprendem 
a colaborar com o colega e a brincarem, em coletivo. Se a sala é reorganizada com frequência, as crianças precisam também explorar esses novos arranjos e reinventar suas brincadeiras de acordo com os novos espaços. Isso contribui para novas aprendizagens, incentivando outras maneiras de experimentarem a cultura lúdica infantil. Sendo assim, é indicada uma organização que contemple espaços mais abertos e, em outras situações, mais fechados.

A partir desta pesquisa, verificou-se que esse grupo de crianças preferiu brincar embaixo da mesa, em vários dias de coleta de dados.

A professora junta as três mesas da sala.

Hulk, Homem Aranha e Ben 10 estão embaixo de uma delas. Aproximo-me da mesa.

Pesquisadora: Quanta gente aqui!

Hulk: Aqui é a caverna. Cuidado! Aqui é a caverna do dragão.

Ana, Rebeca, Moranguinho e Daiane estão embaixo de outra mesa.

Ana: Pro! Ó, estamos na cabana.

Pouco tempo depois volto a observar as meninas que estão embaixo da mesa, ao me aproximar delas Ana diz:

Ana: Sai daqui.

Pesquisadora: Por quê?

Ana: Essa é a nossa casa. Não vai entrar na nossa casa, porque tem um monte de gente aqui.

Pesquisadora: Vou ficar aqui do lado de fora. (Diário de Campo número $5-29 / 08 / 14)$

Todos os meninos vão para baixo da mesa.

Pesquisadora: Posso ficar aqui com vocês?

Homem Aranha: Está apertado.

Pesquisadora: Mas eu fico do lado de fora.

Ben 10 e Ale trocam os brinquedos: Ben 10 entrega seu carro Avalanche, $e$ Ale lhe dá o relógio do personagem Ben 10.

Pesquisadora: O que vocês estão fazendo aí?

Ale: Estamos escondendo do lobo mau. Já, já ele vai chegar.

Ben 10 levanta seu braço que está com o relógio e diz:

Ben 10: Não! Eu sou o super Bem. (Diário de Campo número 12 -24/10/14)

Locais mais fechados como embaixo da mesa são chamados de zonas circunscritas, ou seja, aquelas que são fechadas em pelo menos três lados. Nos espaços circunscritos, é que as crianças preferem brincar com outras crianças. $E$ nestes espaços, também, que as brincadeiras de faz-de-conta ocorrem com mais frequência (CARVALHO; MENEGHINI, 2009). 
Quando as crianças estavam brincando embaixo da mesa, caso algum adulto se aproximasse, elas diziam que estava muito cheio, que não poderia entrar mais alguém ou então pediam para que essa pessoa saísse do local. De acordo com Carvalho e Meneghini (2009), as zonas circunscritas oferecem privacidade e proteção, por manterem as crianças longe das solicitações dos adultos, possibilita que elas possam ter mais atenção em seus fazeres e também nas ações de outras crianças. Assim, aumentam as chances de as crianças brincarem juntas e por mais tempo. Isso pode justificar a atitude das crianças em relação aos adultos, nesse contexto investigado.

No entanto o fato de as crianças brincarem embaixo da mesa, procurando por mais privacidade, não deve impossibilitar o professor de se atentar ao que está ocorrendo nesse local, pois, por proporcionar mais liberdade das ações e uma relação mais próxima entre as crianças, nas zonas circunscritas devem ocorrer muitos processos de ensinar e de aprender relacionados ao contexto da brincadeira, as relações de amizade e também de autonomia, pois, já que estão "longe" da presença adulta, as crianças podem tentar solucionar seus conflitos e possíveis problemas sozinhas.

Sendo assim, o professor que sabe da importância das zonas circunscritas organiza o espaço da sala, oportunizando às crianças vivenciarem suas brincadeiras não apenas embaixo da mesa, mas também trazendo caixas de papelão, por exemplo, e/ou outros tipo de mobílias que possibilitem brincadeiras mais preservadas e diferentes formas de organização, pois, trabalhando somente com as mesas, esse espaço não sofrerá muitas modificações.

Rinaldi (2002) informa que o espaço de sala deve ser acolhedor, aconchegante, estimulante e seguro, e não deve ser muito estático. Para a autora (RINALDI, 2002), a partir da organização do espaço, podemos estabelecer tipos de relações entre as crianças e com os professores. Ao discorrer sobre os espaços, ela se refere à organização espacial das escolas de Reggio Emilia5: "Tentamos promover as relações e a colaboração em grupo, bem como enaltecer as identidades individuais e o espaço pessoal. Tentamos estimular a investigação e o intercâmbio, a cooperação e o conflito" (RINALDI, 2002, p. 79).

\footnotetext{
5 "Reggio Emilia é uma cidade de 130.000 habitantes na região próspera e progressista de Emilia Romagna, no nordeste da Itália. Seu sistema municipal de educação para a primeira infância tornou-se reconhecido e aclamado como um dos melhores sistemas de educação no mundo" (EDWARDS; GANDINI; FORMAN, 1999, p. 21).
} 
Entretanto, mediante a pesquisa realizada, questionamos: quais são as reais possibilidades que a professora possui para modificar a sala ou utilizar outros espaços, em um contexto de instituição que atende duas turmas em uma mesma sala (manhã e tarde), o que ocasiona um volume de materiais e móveis, tendo ainda pouco ou um inadequado espaço externo?

Cabe dizer que a organização espacial não deve ser seguida, da mesma maneira, em todas as instituições. Os espaços são diferentes em cada uma e são vividos por crianças de contextos distintos, com histórias e culturas distintas. Horn (2004) destaca que é imprescindivel considerar as vontades e o protagonismo das crianças, os espaços que elas mais se familiarizaram, que mais gostam de ficar e a organização adequada para suas necessidades.

Muitas vezes, os espaços são modificados a partir das experiências e das explorações realizadas pelas crianças. Para Bondavalli (citado por GANDINI, 2002), o espaço fica mais cheio de vida quando agimos de acordo com os interesses e ideias das crianças. Nesse sentido, o professor deve ficar atento a exploração e interações que ocorrem nos espaços organizados por ele, com vistas a atender as expectativas das crianças, no modo como ela pretende ou escolhe agir.

Em momentos pontuais, a professora conduziu breves ações lúdicas com pequenos agrupamentos infantis. Mediante a contribuição docente, compreendemos que a experiência de brincar com a figura adulta atuou como elemento crucial no processo de ressignificação de tempos e lugares para a fantasia, para a imaginação, estruturando o ambiente de sala com atividades construídas e compartilhadas entre os pares e adultos, imersos em valores próprios e significados (BORBA, 2007).

As posturas das crianças, nesse contexto, sugerem que a Educação Infantil é um espaço e tempo de aprendizagem e desenvolvimento de conhecimentos, de expressão de saberes, bem como um lugar para brincar e compartilhar espaços físicos para realização de experiências lúdicas, em agrupamentos infantis. Mediante tais ponderações, como a instituição de educação infantil pode apoiar a construção de significados atribuídos pelas crianças aos seus respectivos espaços, em função da margem de liberdade que estes (como a sala) oferecem às relações infantis?

A sala e a instituição de educação infantil podem oportunizar com mais ou menos incentivo para exploração, descobertas e relações os espaços pré-organizados para brincar. Destacamos que, ao impossibilitar que uma brincadeira 
se realize ou se desenvolva em sala, afastamos a oportunidade de conhecimento sobre um contexto imaginado e produzido pela própria criança, da possibilidade da invenção e da criação como protagonista de seu brincar e, assim, autora em sua experiência lúdica. Isso pode promover uma fragilidade na 'escuta' das ações infantis, pouco aproveitando destas como premissas para potencializar uma qualificada oportunidade educativa para as crianças.

Korczak (1981), Rinaldi (2002) e Larrosa (2013) realçam a relevância da sensibilidade ao escutar, visto que, partindo dessa sensibilidade, possibilitamos às crianças formar e comunicar suas representações construídas e atribuídas a um espaço, baseadas não apenas no que já está conformado para tal espaço, mas também naquilo que se aprende sobre o contexto de troca por comunicação e interação com os outros.

Na Educação Infantil, o espaço deve ser compreendido como um contexto educativo e curricular, e não neutro, pois, a partir dele, oportunizamos diferentes aprendizagens para as crianças (BRASIL, 2010). Desse modo, o papel do adulto na organização dos espaços é fundamental para pensar e propor ambientes desafiadores, que promovam atividades coletivas, incentivando as crianças a exercerem a autonomia. Com isso, o espaço também é um elemento educativo nas experiências de brincar.

Entretanto uma organização espacial que potencialize atividades independentes por parte das crianças, não faz com que a relação com o professor seja menos importante para a aprendizagem delas (HORN, 2004). Para Guimarães e Kramer (2009), o espaço pode tanto promover o desenvolvimento de habilidades e sensações, como também pode ser um local de vigilância e controle das ações infantis. É fundamental planejar pedagogicamente os espaços, de modo que as relações e experiências infantis sejam incentivadas e possam acontecer.

\section{CONSIDERAÇÕES FINAIS}

Este estudo partiu da perspectiva teórica que compreende as crianças como sujeitos sociais ativos e competentes, pertencentes a distintos grupos sociais, sujeitos concretos e contextualizados, capazes de provocar mudanças nos espaços e tempos por onde transitam. Assim, tendo as brincadeiras como linguagem intensa e privilegiada da criança, como experiência privilegiada do ser criança, realizou-se uma reflexão acerca da organização espacial de sala, na Educação Infantil. 
Ao longo das observações participantes, a convivência dialógica possibilitou ouvir os sujeitos. A partir dessa ótica, foi necessário despir-se de concepções que consideravam as crianças como um projeto de adulto. Para que isto fosse possível, partiu-se da consideração das crianças como competentes para atribuir sentidos e significações às suas realidades e para exercer o protagonismo, em tempos e espaços onde convive. Parafraseando Borba (2008, p. 74-5) “[...] é preciso penetrar verdadeiramente no mundo da criança [...] e compreendê-la do seu próprio ponto de vista. É necessário romper com uma idéia única e universal de infância e entendê-la em sua singularidade [...]".

Nesta pesquisa, as brincadeiras como experiências humanas e intensas nas crianças foram inventadas, atenderam ainda as possibilidades ofertadas pelo espaço, tempo e materiais disponíveis na sala. A postura da professora, em deixar o momento de criar e brincar em pares e com os suportes lúdicos, possibilitou a abertura de férteis terrenos para a articulação de saberes e aprendizagens dessas múltiplas infâncias vividas, nos atuais contextos escolarizados.

Consideramos que a convivência contribuiu tanto para se conhecer melhor as crianças, como para compreender o que ocorre no interior da sala, nos momentos destinados ao brincar livre. Do mesmo modo, contribuiu para entender como as crianças se organizam e se manifestam mediantes as circunstâncias espaciais possibilitadas pela rotina, na Educação Infantil.

O estudo em questão mostrou que os tempos para brincar livremente deveriam ser ampliados. Para que isso possa acontecer, é preciso ainda que professores organizem espaços e materiais para as crianças brincarem não somente em sala, mas terem oportunidades para explorar outros contextos educativos da instituição. É crucial ainda que observem do que e como brincam, para melhor conhecê-las e compreender seus modos de ser e estar no mundo, planejando uma prática educativa centrada no diálogo com as crianças, na permuta entre saberes e experiências, trazendo a dimensão da imaginação e da criação para o cotidiano educativo (BORBA, 2007). Em suma, é essencial que o professor tenha clareza da intencionalidade na organização dos espaços, para oportunizar relações e experiências infantis como melhores oportunidades educativas para as crianças.

Neste ínterim, acrescentamos a necessidade de outras investigações que possam abordar a experiência lúdica na primeira infância, especialmente aprofundando discussões sobre os tempos e os espaços para esse brincar na Educação Infantil. 


\section{REFERÊNCIAS}

ARIÈS, P. História social da criança e da família. 2. ed. Rio de Janeira: Guanabara, 1981.

BACHA, M. N. Déspotas mirins: o poder nas novas famílias. São Paulo: Zagodoni, 2012.

BARDIN, L. Análise de conteúdo. 4. ed. Lisboa: Edições 70, 2009.

BOGDAN, R. C.; BIKLEN, S. K. Notas de campo. In: BOGDAN, R. C.; BIKLEN, S. K. Investigação qualitativa em educação. Porto: Porto Editora, 1994. p. 150-75.

BORBA, A. M. As culturas da infância no contexto da educação infantil. In: VASCONCELLOS, T. (Org.). Reflexões sobre infância e cultura. Niterói, RJ: Eduff, 2008. p. 73-91.

. O brincar como modo de ser e estar no mundo. In: BRASIL. Ensino Fundamental de 9 anos: orientações para a inclusão de crianças com seis anos e idade. 2. ed. Brasília, 2007. p. 33-45.

BRASIL. Lei n. 12.796, de 4 de abril de 2013. Altera a Lei no 9.394, de 20 de dezembro de 1996, que estabelece as diretrizes e bases da educação nacional, para dispor sobre a formação dos profissionais da educação e dar outras providências. Brasília: Presidência da República, Casa Civil, 2013.

. Ministério da Educação. Secretária da Educação Básica. Diretrizes Curriculares Nacionais para a Educação Infantil. Brasília: MEC, SEB, 2010. Disponível em <http:// portal. mec.gov.br/index.php?option=com_docman\&view=download\&alias=9769-diretrizescurriculares-2012\&category_slug=janeiro-2012-pdf\&ltemid=30192>. Acesso em: 4 mar. 2017.

. Ministério da Educação e do Desporto. Secretaria de Educação Fundamental. Referencial Curricular Nacional para a Educação Infantil. Brasília: MEC/SEF, 1998. Volume 1: Introdução.

. Lei Federal n. 8.069, de 13 de julho de 1990. Estatuto da Criança e do Adolescente. Brasília: Presidência da República, Casa Civil, 1990.

. Constituição da República Federativa do Brasil: promulgada em 5 de outubro de 1988. Brasília: Imprensa Oficial da União, 1988. Disponível em: <http://www.planalto.gov. br/ccivil_03/constituicao/constituicaocompilado.htm>. Acesso em: 3 jan. 2017.

BROUGÈRE, G. A criança e a cultura lúdica. Revista da Faculdade de Educação, São Paulo, v. 24, n. 2, jul./dez. 1998.

CARVALHO, M. C.; MENEGHINI, R. Estruturando a sala. In: ROSSETTI-FERREIRA, M. C. et al. (Org.). Os fazeres na Educação Infantil. 11. ed. São Paulo: Cortez; Ribeirão Preto, SP: Creche Carochinha/CINDEDI, 2009. p. 152-3.

CARVALHO, M. C. de. Por que as crianças gostam de áreas fechadas? In: ROSSETI-FERREIRA, M. C. et al. (Org.). Os fazeres na Educação Infantil. 11. ed. São Paulo: Cortez, 2009. p. 10-3. 
Brincando em sala na Educação Infantil? Reflexões acerca da organização dos espaços para experiências na primeira infância

CORSARO, W. Sociologia da infância. 2. ed. Porto Alegre: Artmed, 2011.

COSTA, S. A. O Diário de Campo como dialética intersubjetiva. In: WHITAKER, D. C. A. (Org.). Sociologia rural: questões metodológicas emergentes. Presidente Venceslau, SP: Letras à Margem, 2002. p. 151-8.

CRUZ, S. H. V. A criança fala: a escuta de crianças em pesquisas. São Paulo: Cortez, 2008.

DALARRI, D. A.; KORCZAK, J. O direito da criança ao respeito. Tradução de Yan Michalski. São Paulo: Summus, 1989.

EDWARDS, C.; GANDINI, L.; FORMAN, G. As cem linguagens da criança: a abordagem de Reggio Emilia na educação da primeira infância. Porto Alegre: Artmed, 1999.

FINCO, D. A educação dos corpos femininos e masculinos na Educação Infantil. In: FARIA, A. L. G. (Org.). O coletivo infantil em creches e pré-escolas: falares e saberes. São Paulo: Cortez, 2007. p. 94-119.

FIORI, E. M. Educação libertadora. In: . Textos escolhidos: educação e política. Porto Alegre: L\&PM, 1991. p. 83-95. v. II.

FREIRE, P. Pedagogia da indignação: cartas pedagógicas e outros escritos. São Paulo: Editora UNESP, 2000.

FRIEDMANN, A. Linguagens e culturas infantis. São Paulo: Cortez, 2013.

GANDINI, L. R. Emilia: experimentando a vida na creche. In: GANDINI, L. R.; EDWARDS, C. (Org.). Bambini: a abordagem italiana à educação infantil. Porto Alegre: Artmed, 2002.

GOBBI, M. A.; PINAZZA, M. A. (Org.). Infância e suas linguagens. São Paulo: Cortez, 2014. GUIMARÃES, D.; KRAMER, S. Nos espaços e objetos das creches, concepções de educação e práticas com crianças de 0 a 3 anos. In: KRAMER, S. (Org.). Retratos de um desafio: crianças e adultos na educação infantil. São Paulo: Ática, 2009.

HORN, M. G. S. Sabores, cores, sons, aromas: a organização dos espaços na educação infantil. Porto Alegre: Artmed, 2004.

KISHIMOTO, T. M. O jogo e a educação infantil. São Paulo: Pioneira Thomson Learning, 2003. KORCZAK, J. Quando eu voltar a ser criança. 12. ed. São Paulo: Sammus, 1981.

KUHLMANN, J. M. Infância e educação infantil: uma abordagem histórica. Porto Alegre: Mediação, 1998.

LARROSA, J. B. O enigma da infância: ou o que vai do impossível ao verdadeiro. In:

Pedagogia profana: danças piruetas e mascaradas. Belo Horizonte: Autêntica, $\overline{2013}$. p. 183-98.

LUDKE, M.; ANDRÉ, M. E. D. A. Pesquisa em educação: abordagens qualitativas. São Paulo: E.P.U., 2012. 
MINAYO, M. C. S. Ciência, técnica e arte: o desafio da pesquisa social. In: . Pesquisa social: teoria, método e criatividade. Petrópolis, RJ: Vozes, 1994. p. 9-29.

OLIVEIRA, M. W. Pesquisa e trabalho profissional como espaços e processos de humanização e de comunhão criadora. Caderno CEDES, Campinas, SP, v. 29, n. 79, p. 309-21, set./dez. 2009.

POSTMAN, N. O desaparecimento da infância. Rio de Janeiro: Graphia, 1999.

RINALDI, C. Reggio Emilia: a imagem da criança e o ambiente em que ela vive como princípio fundamental. In: GANDINI, L.; EDWARDS, C. e cols. Bambini: a abordagem italiana à educação infantil. Porto Alegre: Artmed, 2002. p. 75-80.

SILVA, J. R.; LIMA, J. M. A brincadeira na educação infantil: implicações teóricas e práticas para a intervenção docente. Nuances: Estudos sobre Educação, Presidente Prudente, SP, v. 26, número especial 1, p. 55-74, jan. 2015.

SOMMERHALDER, A.; ALVES, F. D. Jogo e a Educação da Infância: muito prazer em aprender. Curitiba: CRV, 2011.

\section{Sobre os autores:}

Maria Elisa Nicolielo: Pedagoga, Mestre e Doutoranda em Educação pelo Programa de Pós-Graduação em Educação (PPGE) da Universidade Federal de São Carlos (UFSCar). Professora de Educação Infantil. E-mail: linicolielo11@gmail.com

Aline Sommerhalder: Docente do PPGE/UFSCar; Docente do Departamento de Teorias e Práticas Pedagógicas/CECH/UFSCar. Doutora em Educação Escolar e Pedagoga. Coordenadora do Grupo de Estudos e Pesquisas sobre Processos Educativos de Crianças em Contextos e do Centro de Pesquisa da Criança e de Formação de Educadores da Infância (CFEI)/CNPq. E-mail: sommeraline1@gmail.com

Fernando Donizete Alves: Docente do PPGE/ UFSCar; Docente do Departamento de Educação Física e Motricidade Humana/CCBS/UFSCar. Doutor em Educação Escolar e Licenciado em Educação Física. Pesquisador do Grupo de Estudos e Pesquisas sobre Processos Educativos de Crianças em Contextose do Centro de Pesquisa da Criança e de Formação de Educadores da Infância (CFEI)/CNPq.

E-mail: fdalves@ufscar.br

\section{Recebido em abril de 2017}

\section{Aprovado em outubro de 2017}

